\title{
Application of a Thermodynamic Consistency Test to Binary Mixtures Containing an Ionic Liquid
}

\author{
Víctor H. Àlvarez and Martín Aznar* \\ School of Chemical Engineering, State University of Campinas, UNICAMP. P.O. Box 6066, 13083-970, Campinas-SP, \\ Brazil
}

\begin{abstract}
A thermodynamic consistency test developed for high pressure binary vapor-liquid mixtures is applied to mixtures containing a supercritical solvent and an ionic liquid. Several authors have reported vapor-liquid equilibrium data on the binary systems supercritical $\mathrm{CO}_{2}+1$-butyl-3-methyl imidazolium hexafluorophosphate $\{[$ bmim] $[\mathrm{PF} 6]\}$, supercritical $\mathrm{CO}_{2}+$ 1-butyl-3-methyl imidazolium nitrate $\left\{[\right.$ bmim $\left.]\left[\mathrm{NO}_{3}\right]\right\}$, supercritical $\mathrm{CO}_{2}+1$-butyl-3-methyl imidazolium tetrafluoroborate $\left\{[\mathrm{bmim}]\left[\mathrm{BF}_{4}\right]\right\}$ and supercritical $\mathrm{CHF}_{3}+$ 1-butyl-3-methyl imidazolium hexafluorophosphate $\left\{[\mathrm{bmim}]\left[\mathrm{PF}_{6}\right]\right\}$, but some of these data differ dramatically. The Peng-Robinson equation of state, coupled with the WongSandler mixing rules, has been used for modeling the vapor-liquid equilibrium of these binary mixtures. Then, the proposed thermodynamic consistency test has been applied. The results show that the consistency test can be applied with confidence, determining consistency or inconsistency of the experimental data.
\end{abstract}

\section{INTRODUCTION}

Recently, Blanchard et al. [1], Pérez-Salado Kamps et al. [2], Liu et al. [3] Aki et al. [4], Shiflett and Yokozeki [5] and Shariati et al. [6] measured the vapor-liquid equilibrium of the binary system supercritical $\mathrm{CO}_{2}+$ [bmim][PF6] at different temperatures. In the same way, Blanchard et al. [1] and Aki et al. [4] reported vapor-liquid equilibrium data for the system supercritical $\mathrm{CO}_{2}+[\mathrm{bmim}]\left[\mathrm{NO}_{3}\right]$; Aki et al. [4], Kroon et al. [7] and Shiflett and Yokozeki [5] studied the system supercritical $\mathrm{CO}_{2}+[\mathrm{bmim}]\left[\mathrm{BF}_{4}\right]$, while Shiflett and Yokozeki [8] and Shariati et al. [6] presented data about the system supercritical $\mathrm{CHF}_{3}+[\mathrm{bmim}]\left[\mathrm{PF}_{6}\right]$. All these data show important discrepancies among the different sets. As an example, all the data for the system $\mathrm{CO}_{2}+[\mathrm{bmim}]\left[\mathrm{PF}_{6}\right]$ at 313.15 K are plotted in Fig. (1); it is easy to see the significant discrepancies among the different data sets. Similar results are obtained at the other temperatures.

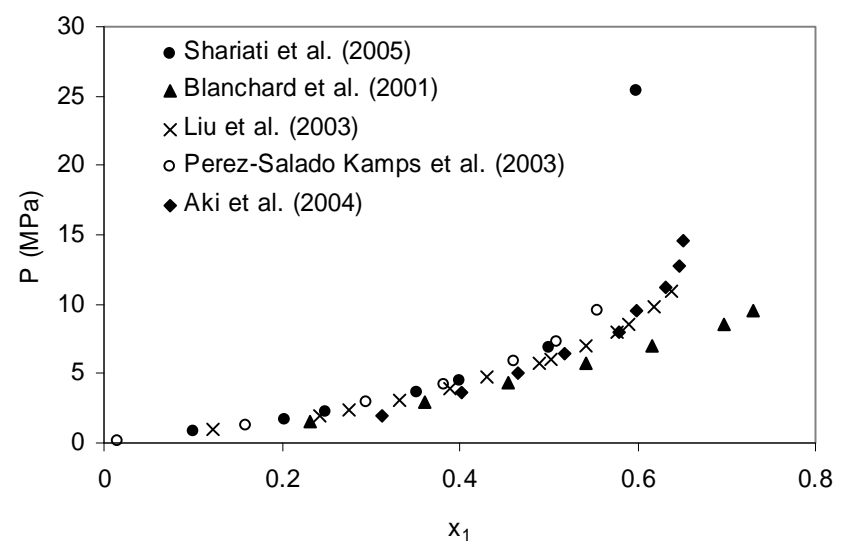

Fig. (1). Phase behavior for system supercritical $\mathrm{CO}_{2}+\left[\mathrm{bmim}\left[\mathrm{PF}_{6}\right]\right.$ at $313.15 \mathrm{~K}$.

\footnotetext{
*Address correspondence to this author at the School of Chemical Engineering, State University of Campinas, UNICAMP, P.O. Box 6066, 13083-970, Campinas - SP, Brazil; Tel: +55-19-3788-3962; Fax: +55-19-3788-3965; E-mail: maznar@feq.unicamp.br
}

These discrepancies are of course due to inaccuracies in measuring experimental properties; this makes necessary to test the inaccuracies inherent of such data. Although it is difficult to be absolutely certain about the exactness of experimental data, it is possible to verify if such data satisfy the Gibbs-Duhem equation, establishing if they are thermodynamic consistent or inconsistent. Good reviews about consistency tests are found in Raal and Mühlbauer [9] and Prausnitz et al. [10]. Jackson and Wilsak [11] analyzed several consistency tests, mainly for complete high pressure VLE data, that is, experimental PTxy data covering the entire concentration range in both phases; the authors conclude that each test provides different information that, sometimes, can bias the operator. Bertucco et al. [12] proposed a consistency test applicable to isothermal, binary VLE data at moderate and high pressures, also for the entire concentration range in both phases. Valderrama and Álvarez [13] presented a new method to test the thermodynamic consistency of incomplete binary VLE data; that is, where PTxy data are not fully available for the entire concentration range, and for low liquid solute concentrations in the vapor phase (mole fractions $<10^{-3}$ ). For these cases, the classic derivative or integral methods are not applicable.

In these tests, the criteria on consistency are always statistical. But any of these tests still cannot decide whether the underlying data are of high or bad quality. This depends on inaccuracies in measuring experimental properties. The consistency tests only can say if the data satisfy or not the thermodynamic constraints imposed by the Gibbs-Duhem equation.

In this work, an extension of the consistency test of Valderrama and Álvarez [13] is applied to four systems supercritical fluid + ionic liquid; this test is useful when the data do not cover the entire concentration range in liquid or gas phase, that is, where PTxy data are not fully available for the entire concentration range, and for low solute liquids concentrations in the vapor phase. So far, few attempts have been done to treat binary mixtures as presented in this work. 
The consistency test for binary gas-ionic liquid mixtures proposed in this work can be considered as a modeling procedure and can be easily extended to other multicomponent mixtures. In the method, a thermodynamic model that can accurately fit the experimental data must be also used to apply the consistency test. The fitting of the experimental data requires the calculation of some model parameters using a defined objective function that must be optimized. The test was first validated with the binary system $\mathrm{CO}_{2}+\mathrm{n}$-butane, and next applied to the binary systems $\mathrm{CO}_{2}+[\mathrm{bmim}]\left[\mathrm{PF}_{6}\right]$, $\mathrm{CO}_{2}+[\mathrm{bmim}]\left[\mathrm{NO}_{3}\right], \mathrm{CO}_{2}+[\mathrm{bmim}]\left[\mathrm{BF}_{4}\right]$, and $\mathrm{CHF}_{3}+$ [bmim] $\left[\mathrm{PF}_{6}\right]$.

The binary mixtures selected for this study present some interesting peculiarities that make them appropriate for the thermodynamic test for binary mixtures that is presented here. The ionic liquid themselves, $[\mathrm{bmim}]\left[\mathrm{PF}_{6}\right],[\mathrm{bmim}]$ $\left[\mathrm{NO}_{3}\right]$ and $[\mathrm{bmim}]\left[\mathrm{BF}_{4}\right]$, present very different physicochemical characteristics and properties, that determine different phase behavior. The $\left[\mathrm{PF}_{6}\right]$ anion was found to hydrolyze completely after addition of excess water at $100^{\circ} \mathrm{C}$ [14]. On the other hand, $[\mathrm{bmim}]\left[\mathrm{NO}_{3}\right]$, as most nitrate salts, is water-miscible, while $[\mathrm{bmim}]\left[\mathrm{PF}_{6}\right]$ is not; ionic liquids with the $\left[\mathrm{BF}_{4}\right]$ anion may be miscible in water or not, depending on the nature of the cation; specifically, $[\mathrm{bmim}]\left[\mathrm{BF}_{4}\right]$ is miscible in water. Table 1 presents some properties of the components of the binary mixtures included in this work. In this table, the critical properties for ionic liquids are from [15], while the structural parameters $r$ and $q$ are from [16].

The mixtures studied also have some special characteristics. For the binary mixtures $\mathrm{CO}_{2}+$ ionic liquid, the concentration of the ionic liquid in supercritical $\mathrm{CO}_{2}$ is so small that it could not be detected with experimental equipment [1-7]. On the other hand, for the binary mixtures $\mathrm{CHF}_{3}+$ ionic liquid, the concentration of the ionic liquid in supercritical $\mathrm{CHF}_{3}$ is appreciable $[6,8]$.

For the systems $\mathrm{CO}_{2}+[\mathrm{bmim}]\left[\mathrm{PF}_{6}\right], \mathrm{CO}_{2}+[\mathrm{bmim}]\left[\mathrm{BF}_{4}\right]$ and $\mathrm{CHF}_{3}+[\mathrm{bmim}]\left[\mathrm{PF}_{6}\right]$, Shariati et al. [6] measured isopleths, i.e. lines at constant overall composition; therefore, their VLE data are obtained by interpolation of the original data. Several authors used different interpolated functions to build a Px diagram [17, 18]. The interpolation method used in this work is discussed in appendix A.

\section{THERMODYNAMIC MODELING}

The thermodynamic relationship used to analyze the thermodynamic consistency of experimental VLE data is the Gibbs-Duhem equation. Once a thermodynamic model (such an equation of state with appropriate mixing and combining rules) accurately fit the data fulfilling the equality of fugacities required by the fundamental phase equilibrium equation, that model is used to check that the Gibbs-Duhem equation is also fulfilled. Once should notice that these two steps, modeling of the data and the application of the GibbsDuhem equation are independent, so that good modeling does not guarantee consistency and that consistent data cannot necessarily be well represented by a defined model. Recently, Álvarez and Aznar [16] and Álvarez et al. [19] presented some results for mixtures $\mathrm{CO}_{2}+$ ionic liquid using the Peng-Robinson [20] equation of state (EoS), and the results showed good agreement with the experimental data. RedlichKong type equations were also used by Shiflett and Yokozeki [5].

The thermodynamic model used to fit the experimental data must be also used to apply the consistency test. Then the proposed test is a modeling procedure, similar to the Van Ness-Byer-Gibbs test [21]. Once the model parameters are determined and the calculated solubilities are within acceptable limits of deviations, the Gibbs-Duhem equation is applied. The equations defining the consistency criteria for binary mixtures have been presented by Valderrama and Álvarez [13]. The development for binary mixtures containing ionic liquids has not been yet presented in the literature, and is summarized as follows.

The test use the Peng-Robinson (PR) EoS with the Wong-Sandler [22] mixing rule, coupled with the UNIQUAC model [23] for the excess Gibbs free energy, as the standard thermodynamic model in a bubble-point calculation; of course, other models could be used. The complete model is described below:

$$
\begin{aligned}
& P=\frac{R T}{V-b}-\frac{a}{V(V+b)+b(V-b)} \\
& a=a_{c} \alpha(T) \\
& a_{c}=0.457235\left(R_{c} / P_{c}\right)^{2}
\end{aligned}
$$

\begin{tabular}{|c|c|c|c|c|c|c|}
\hline carbon dioxide & $44.01^{\mathrm{a}}$ & $304.21^{\mathrm{a}}$ & $7.383^{\mathrm{a}}$ & $0.2236^{\mathrm{a}}$ & $3.26^{\mathrm{b}}$ & $2.39^{\mathrm{b}}$ \\
\hline n-butane & $284.18^{\mathrm{d}}$ & $708.9^{c}$ & $1.73^{\mathrm{c}}$ & $0.7553^{\mathrm{c}}$ & $24.01^{\mathrm{b}}$ & $15.16^{\mathrm{b}}$ \\
\hline$[\mathrm{bmim}]\left[\mathrm{PF}_{6}\right]$ & $226.02^{\mathrm{d}}$ & $632.3^{c}$ & $2.04^{\mathrm{c}}$ & $0.8489^{\mathrm{c}}$ & $21.75^{\mathrm{d}}$ & $14.08^{\mathrm{d}}$ \\
\hline$[\mathrm{bmim}]\left[\mathrm{NO}_{3}\right]$ & $44.01^{\mathrm{a}}$ & $304.21^{\mathrm{a}}$ & $7.383^{\mathrm{a}}$ & $0.2236^{\mathrm{a}}$ & $3.26^{\mathrm{b}}$ & $2.39^{\mathrm{b}}$ \\
\hline
\end{tabular}

Table 1. Properties of Compounds Used in This Work

${ }^{\mathrm{a}}$ Diadem Public[31], ${ }^{\mathrm{b}}$ Álvarez and Aznar [16], ${ }^{\mathrm{c}}$ Valderrama and Robles [15], ${ }^{\mathrm{d}}$ this work. 
$\mathrm{b}=0.077796\left(\mathrm{RT}_{\mathrm{c}} / \mathrm{P}_{\mathrm{c}}\right)$

$\alpha(T)=\left[1+F\left(1-T_{r}^{0.5}\right)\right]^{2}$

$\mathrm{F}=0.37464+1.54226 \omega-0.26992 \omega^{2}$

where $T_{r}$ is the reduced temperature, $T_{c}$ is the critical temperature, $P_{c}$ is the critical pressure, $R$ is the gas constant, and $\omega$ is the acentric factor. For mixtures:

$\mathrm{P}=\frac{\mathrm{RT}}{\mathrm{V}-\mathrm{b}_{\mathrm{m}}}-\frac{\mathrm{a}_{\mathrm{m}}}{\mathrm{V}\left(\mathrm{V}+\mathrm{b}_{\mathrm{m}}\right)+\mathrm{b}_{\mathrm{m}}\left(\mathrm{V}-\mathrm{b}_{\mathrm{m}}\right)}$

The mixture constants $a_{m}$ and $b_{m}$ are expressed by the Wong-Sandler (WS) mixing rules:

$$
\begin{aligned}
& b_{m}=\frac{\sum_{i} \sum_{j} x_{i} x_{j}\left(b-\frac{a}{R T}\right)_{i j}}{1-\sum_{i} \frac{x_{i} a_{i}}{b_{i} R T}-\frac{A_{\infty}^{E}}{\Omega R T}} \\
& a_{m}=b_{m}\left[\sum_{i} \frac{x_{i} a_{i}}{b_{i}}+\frac{A_{\infty}^{E}}{\Omega}\right] \\
& \left(b-\frac{a}{R T}\right)_{i j}=\frac{\left(b_{i}+b_{j}\right)}{2}-\frac{\left(1-k_{i j}\right) \sqrt{a_{i} a_{j}}}{R T}
\end{aligned}
$$

where $\Omega=\ln (\sqrt{2}-1) / \sqrt{2}$ for PR EoS, $\mathrm{x}$ is the molar fraction, $\mathrm{A}_{\infty}{ }^{\mathrm{E}}$ is the excess Helmholtz energy at infinite pressure and $\mathrm{k}_{\mathrm{ij}}$ is a binary interaction parameter.

The excess Helmholtz energy at infinite pressure $\mathrm{A}_{\infty}{ }^{\mathrm{E}}$ can be approximated by the excess Gibbs energy at zero pressure $\mathrm{G}_{\infty}{ }^{\mathrm{E}}[24]$, and the latter can be expressed by the UNIQUAC model [23] as:

$\mathrm{G}^{\mathrm{E}}=\mathrm{G}_{\mathrm{comb}}^{\mathrm{E}}+\mathrm{G}_{\mathrm{res}}^{\mathrm{E}}$

$\frac{\mathrm{G}_{\mathrm{comb}}^{\mathrm{E}}}{\mathrm{RT}}=\sum_{\mathrm{i}} \mathrm{x}_{\mathrm{i}} \ln \frac{\Phi_{\mathrm{i}}^{*}}{\mathrm{x}_{\mathrm{i}}}+\frac{\mathrm{z}}{2} \sum_{\mathrm{i}} \mathrm{q}_{\mathrm{i}} \mathrm{x}_{\mathrm{i}} \ln \frac{\theta_{\mathrm{i}}}{\Phi_{\mathrm{i}}^{*}}$

$\frac{\mathrm{G}_{\mathrm{res}}^{\mathrm{E}}}{\mathrm{RT}}=-\sum_{\mathrm{i}} \mathrm{q}_{\mathrm{i}} \mathrm{x}_{\mathrm{i}} \ln \left(\sum_{\mathrm{j}} \theta_{\mathrm{j}} \tau_{\mathrm{ji}}\right)$

$\Phi_{\mathrm{i}}^{*}=\frac{\mathrm{r}_{\mathrm{i}} \mathrm{x}_{\mathrm{i}}}{\sum_{\mathrm{j}} \mathrm{r}_{\mathrm{j}} \mathrm{x}_{\mathrm{j}}}$

$\theta_{\mathrm{i}}=\frac{\mathrm{q}_{\mathrm{i}} \mathrm{x}_{\mathrm{i}}}{\sum_{\mathrm{j}} \mathrm{q}_{\mathrm{j}} \mathrm{x}_{\mathrm{j}}}$

$\tau_{i j}=\exp \left(-\frac{A_{i j}}{R T}\right)$

where $A_{i j}$ and $A_{j i}$ represent the interaction energy between molecules $i$ and j. $\Phi_{i}{ }^{*}$ and $\theta^{i}$ are the volume and surface area fractions, $\mathrm{z}$ is the coordination number $(\mathrm{z}=10)$, and $\mathrm{r}$ and $\mathrm{q}$ are the structural parameters for the volume and surface area.
For the modeling, the relative deviations in the pressure and solute concentration in the gas phase for data point " $i$ " are defined as:

$$
\begin{aligned}
& \% \Delta \mathrm{P}_{\mathrm{i}}=100\left(\mathrm{P}_{\mathrm{i}}^{\mathrm{cal}}-\mathrm{P}_{\mathrm{i}}^{\exp }\right) / \mathrm{P}_{\mathrm{i}}^{\exp } \\
& \% \Delta y_{2 i}=100\left[\left(y_{2}^{c a l}-y_{2}^{\exp }\right) / y_{2}^{\exp }\right]_{i}
\end{aligned}
$$

The proposed test uses the Gibbs-Duhem equation expressed in the integral form:

$\int \frac{1}{\mathrm{Py}_{2}} \mathrm{dP}=\int \frac{\left(1-\mathrm{y}_{2}\right)}{\mathrm{y}_{2}(\mathrm{Z}-1)} \frac{\mathrm{d} \phi_{1}}{\phi_{1}}+\int \frac{1}{(\mathrm{Z}-1)} \frac{\mathrm{d} \phi_{2}}{\phi_{2}}$

where $\mathrm{P}$ is the pressure of the system, $\mathrm{y}_{2}$ is the mole fraction of the ionic liquid in the gas phase, $\phi_{1}$ and $\phi_{2}$ are the fugacity coefficients of the component 1 and 2 in the gas phase, and $\mathrm{Z}$ is the compressibility factor. Both sides of this equation are denoted as follows:

$$
\begin{aligned}
& A_{P}=\int \frac{1}{P_{2}} d P \\
& A_{\phi}=\int \frac{\left(1-y_{2}\right)}{y_{2}(Z-1)} \frac{d \phi_{1}}{\phi_{1}}+\int \frac{1}{(Z-1)} \frac{d \phi_{2}}{\phi_{2}}
\end{aligned}
$$

The values for $A_{P}$ are obtained with experimental $\mathrm{Py}_{2}$ data, while the values for $A_{\phi}$ are obtained with calculated values of $\mathrm{Z}, \phi_{\mathrm{i}}$ and $\mathrm{y}_{2}$. Thus, for one data set to be considered as consistent, $A_{\phi}$ and $A_{P}$ should be similar within acceptable deviations. In order to define the acceptable deviations, an individual percent area deviation $\left(\% \Delta \mathrm{A}_{\mathrm{i}}\right)$ between the $\mathrm{A}_{\phi}$ and $A_{P}$ values can be defined as:

$\% \Delta A_{i}=100\left[\left(A_{\phi}-A_{P}\right) / A_{P}\right]_{i}$

This is the parameter that determines the consistency of the data set.

The method implies the minimization of the deviations, Eqs. (20), (21) and (22), where the experimental values of concentration of ionic liquid in the gas phase $\left(\mathrm{y}_{2}\right)$ are needed; however, since these concentrations are almost negligible, its measurement is difficult [6]; this is the basis for the physical criterion for values of $y_{2}$, and this value can be lesser than $10^{-3}$ with an experimental uncertainties of $10^{-5}$. These values are empirically based in different experimental results for solubility of solids in gas. Therefore, the consistency test presented here use values for $\mathrm{y}_{2}$ calculated through the bubble pressure calculation, restricted only for values not well detected with equipments to be used as physically significant values in Eqs. (18) and (19). As a comparison, Banerjee et al. [25] predicted $\mathrm{y}_{\text {fluid }}$ values in the range 0.99-1.00.

The objective function for the consistency test includes a minimization of deviations in VLE data, and the integral areas $\left(\% \Delta \mathrm{A}_{\mathrm{i}}\right)$. The inclusion of vapor concentrations in the objective function allows low deviations in pressure and predicts true physical concentrations in the vapor phase [13]. Then the consistency of VLE data set is tested by the objective function, $\mathrm{OF}$, 


$$
\begin{aligned}
\mathrm{OF}= & \sum_{\mathrm{i}=1}^{\mathrm{N}-1}\left[\frac{\mathrm{A}_{\mathrm{P}}-\mathrm{A}_{\phi}}{\sigma_{\mathrm{A}}}\right]_{\mathrm{i}}^{2} \\
& +\sum_{\mathrm{i}=1}^{\mathrm{N}}\left[\frac{\mathrm{P}^{\mathrm{cal}}-\mathrm{P}^{\mathrm{exp}}}{\sigma_{\mathrm{P}}}\right]_{\mathrm{i}}^{2}+\sum_{\mathrm{i}=1}^{\mathrm{N}}\left[\frac{\mathrm{y}_{\text {fluid }}^{\text {cal }}-1}{\sigma_{\mathrm{y}}}\right]_{\mathrm{i}}^{2}
\end{aligned}
$$

where $\mathrm{N}$ is the number of data points, $\mathrm{P}$ is the pressure, $\mathrm{y}_{\text {fluid }}$ is the vapor mole fraction of the supercritical fluid for data point $i$, the superscripts "exp" and "cal" refers to the experimental and calculated values respectively, and $\sigma_{A}, \sigma_{P}$ and $\sigma_{y}$ are the standard deviations of the measured quantities. For simplification, the experimental uncertainties (or interpolation errors) of the pressure data were used for $\sigma_{\mathrm{P}}$, the value $10^{-5}$ (or $10^{-3}$ when there are dew point data) for $\sigma_{\mathrm{y}}$ and the value of $A_{P}$ for $\sigma_{A}$. Equation (23) was used to put a reasonable weight on the measured quantities according to their experimental accuracy. The accepted deviation defined by $\% \Delta \mathrm{P}<10$ is used as constraint for every data point in the minimization method. The minimization method was performed using a genetic algorithm code, implemented and fully explained in Álvarez et al. [19].

There are three possible answers for the consistency test: (i) the data are thermodynamically consistent (TC); (ii) the data are not fully consistent (NFC); and (iii) the data are thermodynamically inconsistent (TI). When individual pressure and area deviations are greater than a defined limit, the worst data point is eliminated and the remaining data set is analyzed. If this data set passes the test, the conclusion is that the original data are not fully consistent and the remaining data set is thermodynamically consistent.

These intervals defined for consistency criteria are based on information presented in the literature related to the accuracy of experimental data for this type of mixtures (ionic liquids, solids and heavy alkanes dissolved in a high pressure gas) and on the criteria used by Valderrama and Álvarez [13]. In order to analyze the limits for consistency criteria, calculations of error propagation on the measured experimental data have been performed by using the general equation of error propagation [26], with the liquid phase mole fraction, the temperature and the interaction parameters as the independent measured variables. The calculated individual area $A_{\phi}$, evaluated using two consecutive points, is the dependent variable. The error (EA) and the percent error $(\% \Delta \mathrm{EA})$ in the calculated area are:

$$
\begin{aligned}
& \mathrm{EA}=\left|\frac{\partial \mathrm{A}_{\phi}}{\partial \mathrm{x}}\right| \Delta \mathrm{x}+\left|\frac{\partial \mathrm{A}_{\phi}}{\partial \mathrm{T}}\right| \Delta \mathrm{T}+\left|\frac{\partial \mathrm{A}_{\phi}}{\partial \mathrm{k}_{\mathrm{ij}}}\right| \Delta \mathrm{k}_{\mathrm{ij}} \\
& +\left|\frac{\partial \mathrm{A}_{\phi}}{\partial \mathrm{A}_{\mathrm{ij}}}\right| \Delta \mathrm{A}_{\mathrm{ij}}+\left|\frac{\partial \mathrm{A}_{\phi}}{\partial \mathrm{A}_{\mathrm{ji}}}\right| \Delta \mathrm{A}_{\mathrm{ji}} \\
& \% \Delta \mathrm{EA}=100 \mathrm{EA} / \mathrm{A}_{\phi}
\end{aligned}
$$

In this work, there were admitted maximum uncertainties of 0.005 for the experimental liquid phase mole fraction, 0.5 $\mathrm{K}$ for the temperature, and $1 \%$ for each interaction parameter. The error propagation was refined because the interaction parameters were used as independent variables. The partial derivatives in Eq. (19) were numerically calculated for several mixtures, giving a direct relationship between the estimated percent errors \%EA and the relative percent deviations of the pressure $\% \Delta \mathrm{P}$. For a thermodynamically consistent data, a VLE fit yields minimal deviations in the individual areas; a $\% \Delta \mathrm{P}_{\mathrm{i}}$ below that $5 \%$ yields $\% \Delta \mathrm{A}_{\mathrm{i}}$ below that $10 \%$ and a $\% \Delta \mathrm{P}_{\mathrm{i}}$ between $5 \%$ up to $10 \%$ yields $\% \Delta \mathrm{A}_{\mathrm{i}}$ below that $20 \%$. Over these limits, the experimental data has high chance to be thermodynamically inconsistent. These limits defined for the consistency criterion produce randomly distributed deviations on VLE.

Then, according the study on error propagation studied and the observations by Valderrama and Alvarez [13], the maximum deviation must be within the range $-20 \%$ to $+20 \%$ for $\% \Delta \mathrm{A}_{\mathrm{i}}$ and -10 to +10 for $\% \Delta \mathrm{P}_{\mathrm{i}}$. Of course, these limits are not strict. When only one data point is slightly out of limits, the data set can be consider thermodynamic consistent. However, if several data points are out of limits, there is an evident tendency of inconsistency. The rule of thumb for remove bad data points is: (i) data point with $\% \Delta \mathrm{P}_{\mathrm{i}}>10$ and $\% \Delta \mathrm{A}_{\mathrm{i}}>20$; (ii) data point with $\% \Delta \mathrm{A}_{\mathrm{i}}>20$; (iii) data point with $\% \Delta \mathrm{P}_{\mathrm{i}}<5$ and $\% \Delta \mathrm{A}_{\mathrm{i}}>10$.

This procedure is applied when there are less than 50\% of the individual areas with deviations in the limits defined. If it is not the case, the data set is considered thermodynamically inconsistent. The empirical value of $50 \%$ is based in robust regression theory, which says that more than $50 \%$ of spurious data destroy the tendency of data, showing that the data have systematic experimental error [27]. When the thermodynamic model cannot fit more than $30 \%$ of data points in the data set within the limits defined for individual pressure and ionic liquid concentration in the gas phase, another thermodynamic model should be used.

\section{RESULTS}

Twenty-eight isotherms for five binary mixtures were chosen to show the application of the proposed thermodynamic consistency test. The mixtures were carefully selected so that several phase behavior and features of the test could be emphasized.

In the discussion below, the difference between experimental and calculated values is calculated as the average percent deviation, expressed in absolute form [28], as follows:

$$
\begin{aligned}
& \%|\Delta \mathrm{P}|=\frac{100}{\mathrm{~N}} \sum_{\mathrm{i}=1}^{\mathrm{N}}\left[\left|\mathrm{P}_{\mathrm{i}}^{\mathrm{cal}}-\mathrm{P}_{\mathrm{i}}^{\exp }\right| / \mathrm{P}_{\mathrm{i}}^{\exp }\right] \\
& \%\left|\Delta \mathrm{y}_{2}\right|=\frac{100}{\mathrm{~N}} \sum_{\mathrm{i}=1}^{\mathrm{N}}\left[\left|\mathrm{y}_{2 \mathrm{i}}^{\mathrm{cal}}-\mathrm{y}_{2 \mathrm{i}}^{\exp }\right| / \mathrm{y}_{2 \mathrm{i}}^{\exp }\right]
\end{aligned}
$$

The physical properties for all substances are shown in Table 1, where the structural parameters $r$ and $q$ were calculated according to [16]. Tables $\mathbf{2 - 5}$ show all the experimental data. In Table $\mathbf{2}$ and Fig. (1), for the $\mathrm{CO}_{2}+[\mathrm{bmim}]\left[\mathrm{PF}_{6}\right]$ system, the data determined by Blanchard et al. [1], Liu et al. [3] and Aki et al. [4] show greater deviations from the data by Pérez-Salado Kamps et al. [2] or Shariati et al [6]; the discrepancies become even more significant with increasing pressure at constant temperature. In Table $\mathbf{3}$, for the system $\mathrm{CO}_{2}+[\mathrm{bmim}]\left[\mathrm{NO}_{3}\right]$, the data by Blanchard et al. [1] present a lower solubility of $\mathrm{CO}_{2}$ than those by Aki et al. [4]. In 
Table 4, for the system $\mathrm{CO}_{2}+[\mathrm{bmim}]\left[\mathrm{BF}_{4}\right]$, the data by Aki et al. [4] show greater deviations from the data by Kroon et $a l$. [7] or Shiflett and Yokozeki [5]. In Table 5, for the system $\mathrm{CHF}_{3}+[\mathrm{bmim}]\left[\mathrm{PF}_{6}\right]$, the data by Shariati et al. [6] and Shiflett and Yokozeki [8] show the same values in the same pressure range, but the work by Shariati et al. [6] presents data with high pressures. All these discrepancies can be mainly attributed to the different experimental techniques used to measure the solubility, to ionic liquid impurities, and also to ionic liquid degradation [14]. Besides, it is important to note that some of the data from Shariati et al. [6] show liquid-liquid-vapor boundaries; consequently, it is to be expected that this phenomenon highly affects the quality of their vapor-liquid representation in this region of the phase diagram. This complex phase behavior could be the cause for the apparent inconsistencies in the data.

Table 2. Different Reports of VLE for the Supercritical $\mathrm{CO}_{2}$ (1) $+[$ bmim $]\left[\mathrm{PF}_{6}\right]$ (2) System

\begin{tabular}{|c|c|c|c|c|}
\hline \multirow[t]{2}{*}{ NP } & \multicolumn{3}{|c|}{ Range of Data } & \multirow{2}{*}{ Ref } \\
\hline & $\mathbf{T}(\mathbf{K})$ & $\mathbf{P}(\mathbf{M P a})$ & $\mathbf{x}_{1}$ & \\
\hline 8 & 313.15 & $0.8-52.7$ & $0.1-0.7$ & \multirow{3}{*}{ [5] } \\
\hline 8 & 323.15 & $0.9-58.7$ & $0.1-0.7$ & \\
\hline 8 & 333.15 & $1.1-64.0$ & $0.1-0.7$ & \\
\hline 7 & 313.15 & $0.1-9.5$ & $0.02-0.6$ & \multirow{2}{*}{ [2] } \\
\hline 10 & 333.15 & $0.4-9.2$ & $0.04-0.5$ & \\
\hline 7 & 313.15 & $1.5-9.6$ & $0.2-0.7$ & \multirow{3}{*}{ [1] } \\
\hline 7 & 323.15 & $1.7-9.2$ & $0.2-0.7$ & \\
\hline 7 & 333.15 & $1.6-9.3$ & $0.2-0.7$ & \\
\hline 13 & 313.15 & $0.9-10.9$ & $0.1-0.6$ & \multirow{3}{*}{ [3] } \\
\hline 10 & 323.15 & $0.6-11.6$ & $0.1-0.6$ & \\
\hline 9 & 333.15 & $1.5-12.9$ & $0.2-0.6$ & \\
\hline 9 & 323.15 & $0.01-2.0$ & $0.002-0.2$ & [5] \\
\hline 9 & $313.3^{\text {(first) }}$ & $2.0-14.6$ & $0.3-0.6$ & \multirow{4}{*}{ [4] } \\
\hline 6 & $313.3^{\text {(second) }}$ & $1.6-8.7$ & $0.2-0.6$ & \\
\hline 6 & $313.3^{\text {(third) }}$ & $1.4-8.5$ & $0.2-0.6$ & \\
\hline 8 & 333.3 & $1.7-13.2$ & $0.2-0.6$ & \\
\hline
\end{tabular}

The test was applied with the objective function (Eq. 23), the uncertainty for pressure, $\sigma_{\mathrm{P}}=0.05 \%$ and the uncertainty for concentration in the gas phase, $\sigma_{y}=0.001$. The concentrations $\mathrm{y}_{2}$ were calculated through the bubble point and used for $A_{P}$ and $A_{\phi}$. The mixture $\mathrm{CO}_{2}+n$-butane was already examined by Bertucco et al. [12] and Valderrama and Álvarez [13], and has been used here to validate the proposed method. Both papers used the experimental $\mathrm{y}_{2}$ value. For these authors, the original data set is not fully consistent. In the analysis of Valderrama and Álvarez [13], the last two points give $\% \Delta \mathrm{A}_{\mathrm{i}}$ out of the limits; after removing these points, the remaining data set was considered thermodynamically consistent. The results are shown in Table 6. As expected, the original data set was found to be not fully consistent, since the last two points give an area deviation outside the defined range (bold and italic type in Table 6). After removing these points, the model fitted the remaining data set with $\%|\Delta \mathrm{P}|=0.2$ and $\%\left|\Delta \mathrm{y}_{2}\right|=2.1$, and the data set was regarded thermodynamically consistent. In this way, the model predicts consistently the concentrations $\mathrm{y}_{2}$, and yield results that confirm those obtained by other authors. In this calculation, the proposed method shows characteristics of a robust regression [28], since the $\mathrm{y}_{2}$ predicted is correct and outlying points do not have a great influence on the tendency of the bulk data. The data from Blanchard et al. [1], which were discarded in a later work by the same authors, was used as a test for the proposed method, which correctly indicated that this data set was thermodynamically inconsistent.

Table 3. Different Reports of VLE for the Supercritical $\mathrm{CO}_{2}$ (1) $+[$ bmim $]\left[\mathrm{NO}_{3}\right]$ (2) System

\begin{tabular}{|c|c|c|c|c|}
\hline \multirow[t]{2}{*}{ NP } & \multicolumn{3}{|c|}{ Range of Data } & \multirow{2}{*}{ Ref } \\
\hline & $\mathbf{T}(\mathbf{K})$ & P (MPa) & $\mathbf{x}_{1}$ & \\
\hline 7 & 313.15 & $1.5-9.2$ & $0.2-0.5$ & \multirow{2}{*}{ [1] } \\
\hline 7 & 333.15 & $1.8-9.3$ & $0.2-0.5$ & \\
\hline 6 & 313.15 & $1.3-9.3$ & $0.1-0.5$ & \multirow{2}{*}{ [4] } \\
\hline 6 & 333.1 & $1.3-8.9$ & $0.07-0.4$ & \\
\hline
\end{tabular}

Table 4. Different Reports of VLE for the Supercritical $\mathrm{CO}_{2}$ (1) $+[$ bmim $]\left[\mathrm{BF}_{4}\right](2)$ System

\begin{tabular}{|c|c|c|c|c|}
\hline \multirow{2}{*}{ NP } & \multicolumn{3}{|c|}{ Range of Data } & \multirow{2}{*}{ Ref } \\
\hline & $\mathbf{T}(\mathbf{K})$ & $\mathbf{P}(\mathbf{M P a})$ & $\mathbf{x}_{\mathbf{1}}$ & \\
\hline 5 & 298.15 & $1.2-5.1$ & $0.2-0.5$ & {$[4]$} \\
\hline 5 & 298.15 & $0.7-4.8$ & $0.1-0.5$ & {$[7]$} \\
\hline 9 & 298.15 & $0.01-2.0$ & $0.002-0.28$ & {$[5]$} \\
\hline
\end{tabular}

Table 5. Different Reports of VLE for the Supercritical $\mathrm{CHF}_{3}$ (1) $+[$ bmim $]\left[\mathrm{PF}_{6}\right]$ (2) System

\begin{tabular}{|c|c|c|c|c|c|}
\hline \multirow{2}{*}{ NP } & \multicolumn{4}{|c|}{ Range of Data } & \multirow{2}{*}{ Ref } \\
\hline & $\mathbf{T}(\mathbf{K})$ & $\mathbf{P}(\mathbf{M P a})$ & $\mathbf{x}_{\mathbf{1}}$ & $\mathbf{y}_{\mathbf{1}}$ & \\
\hline \hline 9 & 323 & $0.05-2.0$ & $0.005-0.2$ & - & \multirow{2}{*}[5]{} \\
\cline { 1 - 5 } 9 & 348 & $0.01-2.0$ & $0.001-0.2$ & - & \\
\hline 12 & 323 & $0.8-26.2$ & $0.1-0.9$ & $0.956-0.99$ & \multirow{2}{*}[6]{} \\
\cline { 1 - 4 } 12 & 348 & $1.1-37.0$ & $0.1-0.9$ & $0.956-0.99$ & \\
\hline
\end{tabular}


Table 6. Detailed Results for System Supercritical $\mathrm{CO}_{2}(1)+\mathrm{n}-\mathrm{Butane}(2)$ at 344.26 K from [31]

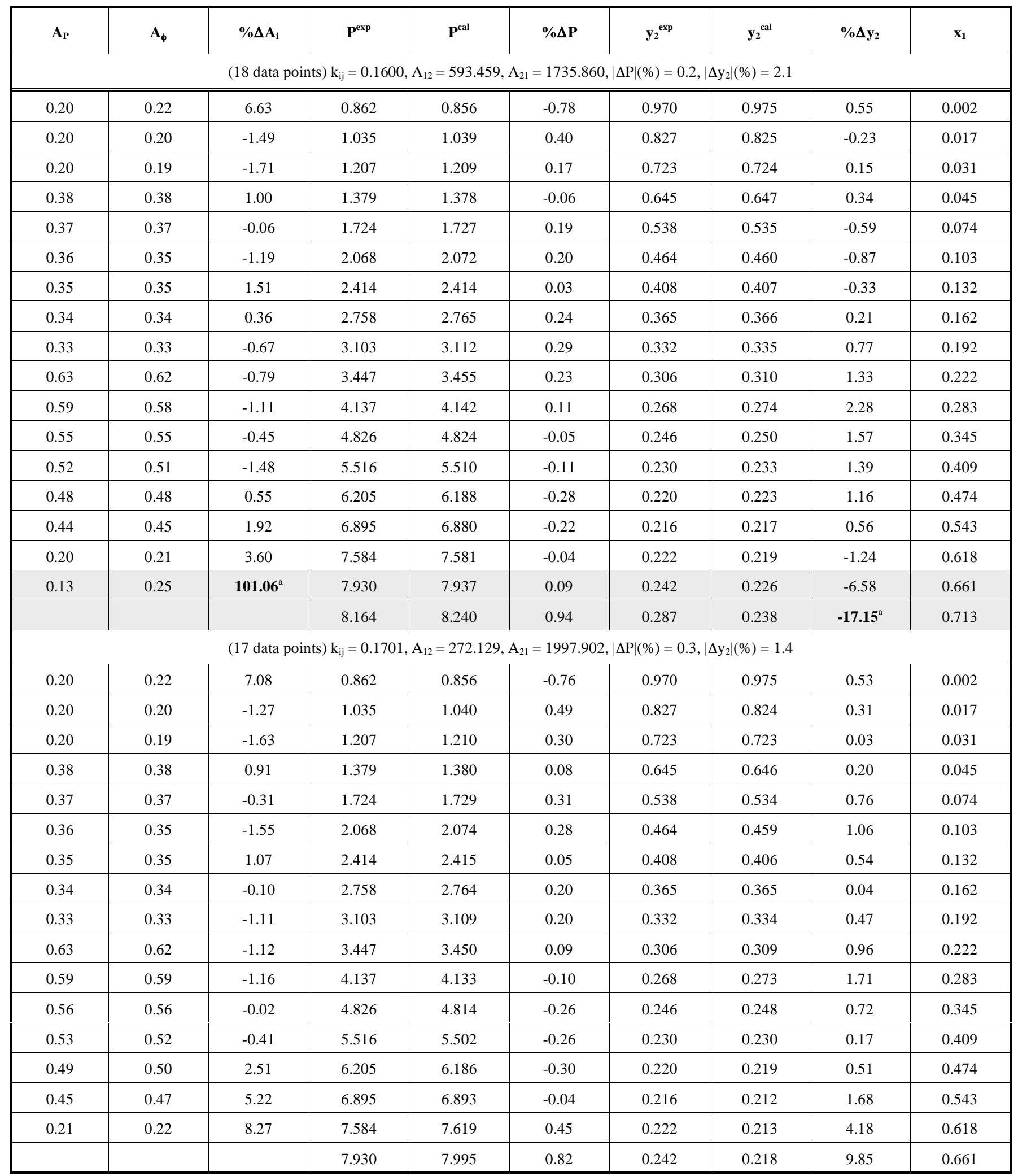

${ }^{\text {a } O u t ~ o f ~ l i m i t s ~ d a t a ~ p o i n t . ~ S h a d e d ~ l i n e: ~ r e m o v e d ~ d a t a ~ p o i n t . ~}$

Table 7 presents results for the application of the test to the binary systems containing ionic liquid. In this table, NP is the number of data points, $\mathrm{T}$ is the temperature, $\mathrm{k}_{\mathrm{ij}}, \mathrm{A}_{12}$ and $A_{21}$ are the interaction parameter of the model, where 1 stands for the supercritical fluid $\left(\mathrm{CO}_{2}\right.$ or $\left.\mathrm{CHF}_{3}\right)$ and 2 stands for the ionic liquid. This table is divided in sections for each system studied. 
Table 7. Results of the Consistency Test Using PR+WS/UNIQUAC, with Estimated $k_{i j}, A_{12}$ and $A_{21}$ Parameters

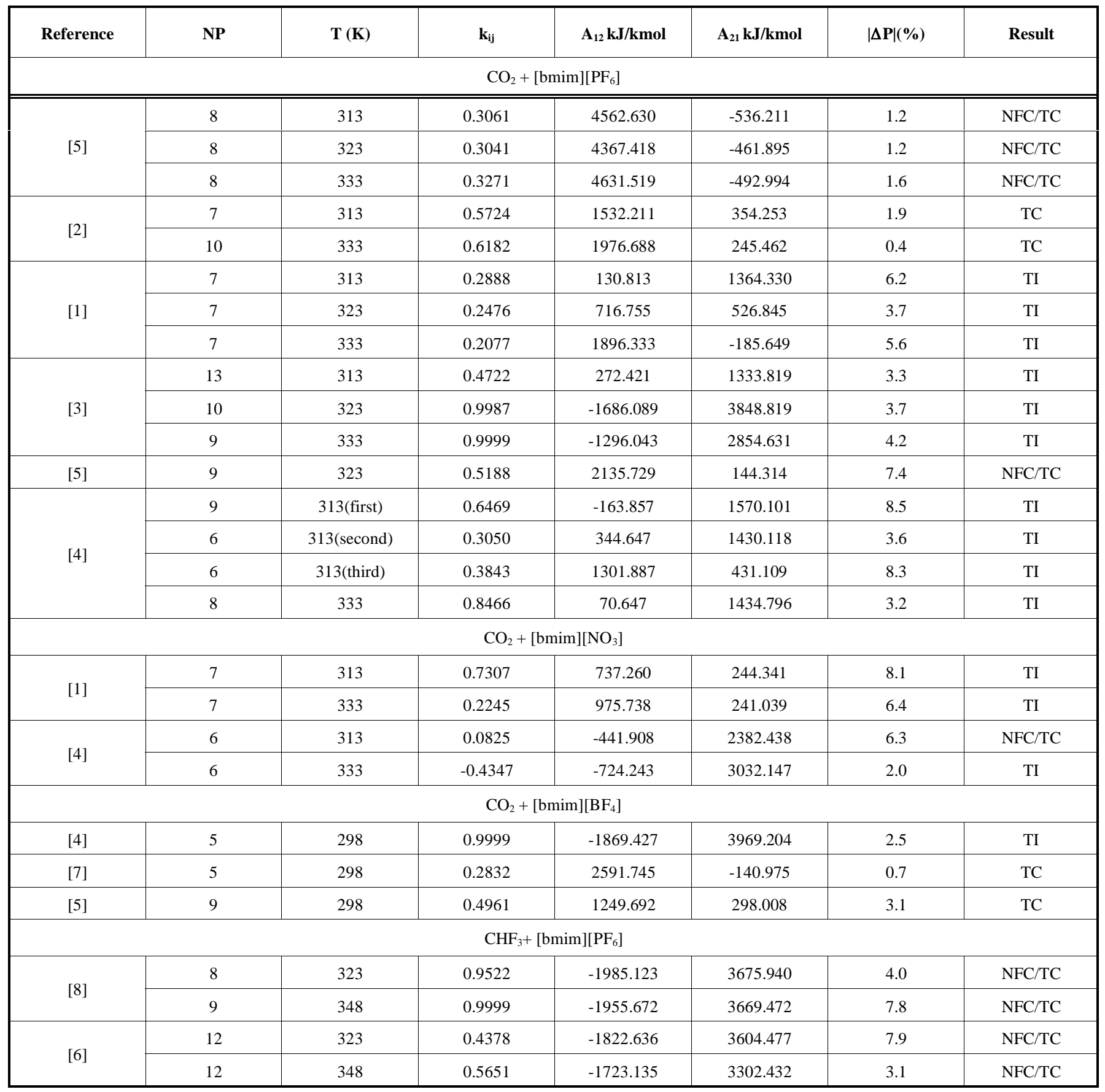

TC: thermodynamically consistent; TI: thermodynamically inconsistent; NFC: not fully consistent.

More detailed results for the system $\mathrm{CO}_{2}+[\mathrm{bmim}]\left[\mathrm{PF}_{6}\right]$ are shown in Tables $\mathbf{8}$ up to 12 . These tables are divided in two parts. The upper part shows the original data set, while the lower part shows the remaining data after removing some points. Each part shows the interaction parameters for the thermodynamic model. Tables 8-10 show detailed results for the data from Shariati et al. [6]. In Table 8, which presents detailed results at $313.15 \mathrm{~K}$, the upper part shows that these data have deviations outside the established limits in the two final values of $\% \Delta \mathrm{A}_{\mathrm{i}}$ (bold and italic type); the lower part shows that, when one point from the original data set is eliminated (the one with the highest area deviation, shaded in the upper part), the deviations for the remaining seven points are within the defined limits of $-20 \%$ to $+20 \%$. Therefore, the original set with eight data points is not fully consistent, but a new set with the remaining seven points is thermodynamically consistent; however, the last point has a high probability to be inconsistent, because two $\% \Delta \mathrm{P}_{\mathrm{i}}<5$ yields $\% \Delta \mathrm{A}_{\mathrm{i}}>10$. The same procedure is applied for the data at 323.15 and $333.15 \mathrm{~K}$, as shown in Tables 9 and 10, respectively; both of data sets are not fully consistent. 
Table 8. Detailed Results for $\mathrm{CO}_{2}+[\mathrm{bmim}]\left[\mathrm{PF}_{6}\right]$ at 313.15 $\mathrm{K}$ from [5]

\begin{tabular}{|c|c|c|c|c|c|c|c|c|}
\hline \multicolumn{9}{|c|}{ (8 data points) $\mathrm{k}_{\mathrm{ij}}=0.3061, \mathrm{~A}_{12}=4562.630, \mathrm{~A}_{21}=-536.211,|\Delta \mathrm{P}|(\%)=1.2$} \\
\hline 243439.9 & 249882.6 & 2.6 & 0.78 & 0.77 & -1.54 & 0.9999957 & 0.0000043 & 0.100 \\
\hline 101610.3 & 99044.5 & -2.5 & 1.74 & 1.75 & 0.50 & 0.9999972 & 0.0000028 & 0.203 \\
\hline 58676.9 & 62042.6 & 5.7 & 3.71 & 3.69 & -0.50 & 0.9999969 & 0.0000031 & 0.351 \\
\hline 84064.8 & 91159.8 & 8.4 & 4.52 & 4.55 & 0.64 & 0.9999962 & 0.0000038 & 0.399 \\
\hline 153996.2 & 178073.3 & $15.6^{\mathrm{a}}$ & 6.91 & 7.20 & 4.22 & 0.9999882 & 0.0000118 & 0.501 \\
\hline 234254.1 & 724645.2 & $209.3^{\mathrm{a}}$ & 25.31 & 24.92 & -1.54 & 0.9999911 & 0.0000089 & 0.598 \\
\hline \multicolumn{9}{|c|}{$(7$ data points $) \mathrm{k}_{\mathrm{ij}}=0.2458, \mathrm{~A}_{12}=4189.500, \mathrm{~A}_{21}=-429.368,|\Delta \mathrm{P}|(\%)=0.6$} \\
\hline 229858.0 & 234248.3 & 1.9 & 0.78 & 0.77 & -0.69 & 0.9999956 & 0.0000044 & 0.100 \\
\hline 91395.4 & 88095.0 & -3.6 & 1.74 & 1.75 & 0.86 & 0.9999970 & 0.0000030 & 0.203 \\
\hline 154891.0 & 150069.9 & -3.1 & 2.28 & 2.28 & -0.09 & 0.9999970 & 0.0000030 & 0.250 \\
\hline 47050.8 & 48479.4 & 3.0 & 3.71 & 3.67 & -1.23 & 0.9999962 & 0.0000038 & 0.351 \\
\hline 64467.2 & 66282.2 & 2.8 & 4.52 & 4.49 & -0.61 & 0.9999951 & 0.0000049 & 0.399 \\
\hline 92311.9 & 80323.9 & $-13.0^{\mathrm{a}}$ & 6.91 & 6.97 & 0.82 & 0.9999833 & 0.0000167 & 0.501 \\
\hline
\end{tabular}

${ }^{a}$ Out of limits data point. Shaded line: removed data point.

Tables 11 and 12 present detailed results for the data from Pérez-Salado Kamps et al. [2], at 313.15 and 333.15 K, respectively; these data are thermodynamically consistent, meaning that all the deviations are within the defined ranges, $-20 \%$ to $20 \%$; however, in both tables the last point has a high probability to be inconsistent, because the two $\% \Delta \mathrm{P}_{\mathrm{i}}<5$ yields $\% \Delta \mathrm{A}_{\mathrm{i}}$ greater than 10 . Tables 13 shows the detailed results for the system $\mathrm{CO}_{2}+[\mathrm{bmim}]\left[\mathrm{NO}_{3}\right]$. The data from Blanchard et al. [1] are thermodynamically inconsistent, since more that $50 \%$ of $\% \Delta \mathrm{A}_{\mathrm{i}}$ showed deviations outside the established limits. Table $\mathbf{1 4}$ shows the detailed results for the system $\mathrm{CO}_{2}+[\mathrm{bmim}]\left[\mathrm{BF}_{4}\right]$, at $298.15 \mathrm{~K}$ from Shiflett and Yokozeki [5] are thermodynamic consistent; in this latter, there is a high probability of inconsistency in the data point $\mathrm{x}_{1}=0.002$, because is the sole data point with $\% \Delta \mathrm{P}=11.94$, slightly out of the limits. Tables $\mathbf{1 5}$ and $\mathbf{1 6}$ show the detailed results for the system $\mathrm{CHF}_{3}+[\mathrm{bmim}]\left[\mathrm{PF}_{6}\right]$. The data from Shiflett and Yokozeki [8] and Shariati et al [6] are not fully consistent. Table 16 shows that Shariati et al. [6] report dew point data, where ionic liquid exists in the gas phase. In this table, $y_{2}$ is an interpolated value for the pressure and the method predicts this concentration of ionic liquid with a deviation less than $3.5 \%$.

\section{CONCLUSIONS}

A thermodynamic model, composed by the PengRobinson EoS coupled with the Wong-Sandler/UNIQUAC mixing rule, was used to accurately correlate experimental vapor-liquid equilibrium data in binary systems containing ionic liquids. The model was also able to predict the low ionic liquid concentrations in the vapor phase. A thermodynamic consistency test based on this model and on the Gibbs-Duhem equation, that allows the analysis of individual data points in a binary vapor-liquid equilibrium data set, i.e., to eliminate doubtful points, was proposed. The test was applied to several data sets from literature involving three ionic liquids and two supercritical solvents. For the system $\mathrm{CO}_{2}+[\mathrm{bmim}]\left[\mathrm{PF}_{6}\right]$, only the original data sets from PérezSalado Kamps et al. [2] are thermodynamically consistent, although the data from Shariati et al. [6] must be considered with care, since they show some liquid-liquid-vapor boundaries, a complex phase behavior which could be the cause for the apparent inconsistencies. For the system $\mathrm{CO}_{2}+$ [bmim] $\left[\mathrm{NO}_{3}\right]$, only the data from Aki et al. [4] at 313.15 are not fully consistent. For the system $\mathrm{CO}_{2}+[\mathrm{bmim}]\left[\mathrm{BF}_{4}\right]$, the data sets from Kroon et al. [7] and Shiflett and Yokozeki [5] are considered thermodynamically consistent. Finally, for the system $\mathrm{CHF}_{3}+[\mathrm{bmim}]\left[\mathrm{PF}_{6}\right]$, all data sets are not fully consistent. 
Table 9. Detailed Results for $\mathrm{CO}_{2}+[\mathrm{bmim}]\left[\mathrm{PF}_{6}\right]$ at 323.15 $\mathrm{K}$ from [5]

\begin{tabular}{|c|c|c|c|c|c|c|c|c|}
\hline $\mathbf{A}_{\mathbf{P}}$ & $\mathbf{A}_{\phi}$ & $\% \Delta \mathbf{A}_{\mathbf{i}}$ & $\mathbf{P}^{\exp }$ & $\mathbf{P}^{\text {cal }}$ & $\% \Delta \mathbf{P}$ & $\mathbf{y}_{1}{ }^{\mathrm{cal}}$ & $\mathbf{y}_{2}{ }^{\mathrm{cal}}$ & $\mathbf{x}_{1}$ \\
\hline \multicolumn{9}{|c|}{$(8$ data points $) \mathrm{k}_{\mathrm{ij}}=0.3041, \mathrm{~A}_{12}=4367.418, \mathrm{~A}_{21}=-461.895,|\Delta \mathrm{P}|(\%)=1.2$} \\
\hline 114652.3 & 117845.3 & 2.8 & 0.93 & 0.91 & -1.45 & 0.999991 & 0.000009 & 0.100 \\
\hline 46947.9 & 44844.3 & -4.5 & 2.07 & 2.08 & 0.73 & 0.999994 & 0.000006 & 0.203 \\
\hline 78068.5 & 77354.9 & -0.9 & 2.74 & 2.72 & -0.47 & 0.999994 & 0.000006 & 0.250 \\
\hline 24264.8 & 25311.3 & 4.3 & 4.46 & 4.44 & -0.57 & 0.999992 & 0.000008 & 0.351 \\
\hline 34438.9 & 36501.6 & 6.0 & 5.47 & 5.49 & 0.35 & 0.999990 & 0.000010 & 0.399 \\
\hline 48309.7 & 66691.5 & $38.1^{\mathrm{a}}$ & 8.70 & 9.01 & 3.56 & 0.999961 & 0.000039 & 0.501 \\
\hline 97440.1 & 450648.4 & $362.5^{\mathrm{a}}$ & 29.24 & 28.75 & -1.66 & 0.999981 & 0.000019 & 0.598 \\
\hline & & & 58.71 & 59.07 & 0.60 & 0.999997 & 0.000004 & 0.650 \\
\hline \multicolumn{9}{|c|}{$(7$ data points $) \mathrm{k}_{\mathrm{ij}}=0.2523, \mathrm{~A}_{12}=3914.281, \mathrm{~A}_{21}=-327.957,|\Delta \mathrm{P}|(\%)=0.6$} \\
\hline 108661.7 & 110901.9 & 2.1 & 0.93 & 0.92 & -0.49 & 0.999991 & 0.000009 & 0.100 \\
\hline 42422.4 & 40082.0 & -5.5 & 2.07 & 2.09 & 1.21 & 0.999993 & 0.000007 & 0.203 \\
\hline 67612.6 & 65771.2 & -2.7 & 2.74 & 2.73 & -0.28 & 0.999993 & 0.000007 & 0.250 \\
\hline 19566.3 & 19897.7 & 1.7 & 4.46 & 4.41 & -1.15 & 0.999991 & 0.000009 & 0.351 \\
\hline 26508.9 & 26525.5 & 0.1 & 5.47 & 5.43 & -0.76 & 0.999987 & 0.000013 & 0.399 \\
\hline 26216.0 & 27204.9 & 3.8 & 8.70 & 8.70 & 0.04 & 0.999943 & 0.000058 & 0.501 \\
\hline & & & 29.24 & 29.24 & 0.00 & 0.999938 & 0.000062 & 0.598 \\
\hline
\end{tabular}

${ }^{\text {a}}$ Out of limits data point. Shaded line: removed data point.

Table 10. Detailed Results for $\mathrm{CO}_{2}+[\mathrm{bmim}]\left[\mathrm{PF}_{6}\right]$ at 333.15 $\mathrm{K}$ from [5]

\begin{tabular}{|c|c|c|c|c|c|c|c|c|}
\hline $\mathbf{A}_{\mathbf{P}}$ & $\mathbf{A}_{\phi}$ & $\% \Delta \mathbf{A}_{\mathbf{i}}$ & $\mathbf{P}^{\exp }$ & $\mathbf{P}^{\text {cal }}$ & $\% \Delta \mathbf{P}$ & $\mathbf{y}_{1}{ }^{\mathrm{cal}}$ & $\mathbf{y}_{2}{ }^{\mathrm{cal}}$ & $\mathbf{x}_{1}$ \\
\hline \multicolumn{9}{|c|}{ (8 data points) $\mathrm{k}_{\mathrm{ij}}=0.3271, \mathrm{~A}_{12}=4631.519, \mathrm{~A}_{21}=-492.994,|\Delta \mathrm{P}|(\%)=1.6$} \\
\hline 58678.7 & 60481.4 & 3.1 & 1.09 & 1.07 & -1.99 & 0.999983 & 0.000017 & 0.100 \\
\hline 23837.0 & 22818.6 & -4.3 & 2.43 & 2.44 & 0.44 & 0.999988 & 0.000012 & 0.203 \\
\hline 39136.6 & 39221.2 & 0.2 & 3.23 & 3.21 & -0.71 & 0.999988 & 0.000012 & 0.250 \\
\hline 12199.5 & 12771.3 & 4.7 & 5.29 & 5.28 & -0.22 & 0.999985 & 0.000015 & 0.351 \\
\hline 19222.2 & 19988.9 & 4.0 & 6.53 & 6.59 & 0.83 & 0.999979 & 0.000021 & 0.399 \\
\hline 41320.0 & 79219.8 & $91.7^{\mathrm{a}}$ & 10.94 & 11.41 & 4.33 & 0.999931 & 0.000069 & 0.501 \\
\hline 132303.0 & 1361502.8 & $929.1^{\mathrm{a}}$ & 34.57 & 33.51 & -3.08 & 0.999987 & 0.000013 & 0.598 \\
\hline & & & 64.04 & 63.29 & -1.16 & 0.999998 & 0.000002 & 0.650 \\
\hline \multicolumn{9}{|c|}{$\left(6\right.$ data points) $\mathrm{k}_{\mathrm{ij}}=0.9854, \mathrm{~A}_{12}=-273.858, \mathrm{~A}_{21}=1824.747,|\Delta \mathrm{P}|(\%)=0.5$} \\
\hline 130003.7 & 132586.3 & 2.0 & 1.09 & 1.08 & -0.40 & 0.9999895 & 0.0000105 & 0.100 \\
\hline 87022.6 & 82412.2 & -5.3 & 2.43 & 2.46 & 1.05 & 0.9999961 & 0.0000039 & 0.203 \\
\hline 261518.7 & 262161.8 & 0.2 & 3.23 & 3.21 & -0.47 & 0.9999973 & 0.0000027 & 0.250 \\
\hline 185890.9 & 193607.5 & 4.2 & 5.29 & 5.26 & -0.49 & 0.9999987 & 0.0000013 & 0.351 \\
\hline 662853.3 & 663250.0 & 0.1 & 6.53 & 6.56 & 0.37 & 0.9999990 & 0.0000010 & 0.399 \\
\hline & & & 10.94 & 10.94 & 0.00 & 0.9999994 & 0.0000006 & 0.501 \\
\hline
\end{tabular}

${ }^{\text {a } O u t ~ o f ~ l i m i t s ~ d a t a ~ p o i n t . ~ S h a d e d ~ l i n e: ~ r e m o v e d ~ d a t a ~ p o i n t . ~}$ 
Table 11. Detailed Results for $\mathrm{CO}_{2}+\left[\mathrm{bmim}_{[}\right]\left[\mathrm{PF}_{6}\right]$ at 313.15 K from [2]

\begin{tabular}{|c|c|c|c|c|c|c|c|c|}
\hline $\mathbf{A}_{\mathbf{P}}$ & $\mathbf{A}_{\phi}$ & $\% \Delta \mathbf{A}_{\mathbf{i}}$ & $\mathbf{P}^{\exp }$ & $\mathbf{P}^{\mathrm{cal}}$ & $\% \Delta \mathbf{P}$ & $\mathbf{y}_{1}{ }^{\text {cal }}$ & $\mathbf{y}_{2}{ }^{\text {cal }}$ & $\mathbf{x}_{1}$ \\
\hline \multicolumn{9}{|c|}{ (7 data points) $\mathrm{k}_{\mathrm{ij}}=0.5724, \mathrm{~A}_{12}=1532.211, \mathrm{~A}_{21}=354.253,|\Delta \mathrm{P}|(\%)=1.9$} \\
\hline 454063.1 & 438556.3 & -3.4 & 1.292 & 1.286 & -0.5 & 0.9999976 & 0.0000024 & 0.1594 \\
\hline 279632.6 & 283292.0 & 1.3 & 2.893 & 2.814 & -2.7 & 0.9999986 & 0.0000014 & 0.2958 \\
\hline 76344.5 & 90541.4 & $18.6^{\mathrm{a}}$ & 7.293 & 7.177 & -1.6 & 0.9999978 & 0.0000022 & 0.5096 \\
\hline & & & 9.480 & 9.652 & 1.8 & 0.9999875 & 0.0000125 & 0.5551 \\
\hline
\end{tabular}

${ }^{a}$ Out of limits data point.

Table 12. Detailed Results for $\mathrm{CO}_{2}+[\mathrm{bmim}]\left[\mathrm{PF}_{6}\right]$ at 333.15 K from [2]

\begin{tabular}{|c|c|c|c|c|c|c|c|c|}
\hline $\mathbf{A}_{\mathbf{P}}$ & $\mathbf{A}_{\phi}$ & $\% \Delta \mathbf{A}_{\mathrm{i}}$ & $\mathbf{P}^{\exp }$ & $\mathbf{P}^{\text {cal }}$ & $\% \Delta \mathrm{P}$ & $\mathbf{y}_{1}{ }^{\text {cal }}$ & $\mathbf{y}_{2}{ }^{\text {cal }}$ & $\mathbf{x}_{1}$ \\
\hline \multicolumn{9}{|c|}{$(10$ data points $) \mathrm{k}_{\mathrm{ij}}=0.6182, \mathrm{~A}_{12}=1976.688, \mathrm{~A}_{21}=245.462,|\Delta \mathrm{P}|(\%)=0.4$} \\
\hline 64236.0 & 63659.3 & -0.9 & 1.75 & 1.74 & -0.2 & 0.9999906 & 0.0000094 & 0.1527 \\
\hline 41086.4 & 41740.7 & 1.6 & 2.89 & 2.87 & -0.6 & 0.9999933 & 0.0000067 & 0.2286 \\
\hline 35797.3 & 35570.3 & -0.6 & 5.81 & 5.81 & 0.0 & 0.9999945 & 0.0000055 & 0.3707 \\
\hline 16312.0 & 16834.6 & 3.2 & 7.09 & 7.08 & -0.1 & 0.9999942 & 0.0000058 & 0.4142 \\
\hline 13887.2 & 12788.9 & -7.9 & 7.82 & 7.84 & 0.2 & 0.9999937 & 0.0000063 & 0.4359 \\
\hline 9750.2 & 11454.1 & $17.5^{\mathrm{a}}$ & 8.56 & 8.52 & -0.5 & 0.9999932 & 0.0000068 & 0.4532 \\
\hline
\end{tabular}

${ }^{a}$ Out of limits data point.

Table 13. Detailed Results for the $\mathrm{CO}_{2}+[\mathrm{bmim}]\left[\mathrm{NO}_{3}\right]$ at $313.15 \mathrm{~K}$ from [1]

\begin{tabular}{|c|c|c|c|c|c|c|c|c|}
\hline $\mathbf{A}_{\mathbf{P}}$ & $\mathbf{A}_{\phi}$ & $\% \Delta \mathbf{A}_{\mathbf{i}}$ & $\mathbf{P}^{\exp }$ & $\mathbf{P}^{\text {cal }}$ & $\% \Delta \mathbf{P}$ & $\mathbf{y}_{1}{ }^{\text {cal }}$ & $\mathbf{y}_{2}^{\text {cal }}$ & $\mathbf{x}_{1}$ \\
\hline \multicolumn{9}{|c|}{ (7 data points) $\mathrm{k}_{\mathrm{ij}}=0.7307, \mathrm{~A}_{12}=737.260, \mathrm{~A}_{21}=244.341,|\Delta \mathrm{P}|(\%)=8.1$} \\
\hline 419272612.9 & 352823607.3 & -15.8 & 2.905 & 2.792 & -3.90 & 1.0 & 0.0 & 0.276 \\
\hline 344310882.7 & 310156934.0 & -9.9 & 4.263 & 3.862 & -9.40 & 1.0 & 0.0 & 0.342 \\
\hline 15815696.6 & 24430743.2 & $54.5^{\mathrm{a}}$ & 8.372 & 8.477 & 1.25 & 1.0 & 0.0 & 0.497 \\
\hline & & & 9.200 & 9.779 & 6.29 & 1.0 & 0.0 & 0.513 \\
\hline \multicolumn{9}{|c|}{ (6 data points) $\mathrm{k}_{\mathrm{ij}}=0.5337, \mathrm{~A}_{12}=73.609, \mathrm{~A}_{21}=1087.130,|\Delta \mathrm{P}|(\%)=4.3$} \\
\hline 208409124.6 & 160663801.3 & $-22.9^{\mathrm{a}}$ & 2.905 & 3.106 & 6.92 & 1.0 & 0.0 & 0.276 \\
\hline 1750040.9 & 2299166.8 & $31.4^{\mathrm{a}}$ & 8.372 & 8.409 & 0.44 & 1.0 & 0.0 & 0.497 \\
\hline & & & 9.200 & 9.493 & 3.18 & 0.9999997 & 0.0000003 & 0.513 \\
\hline
\end{tabular}

${ }^{\mathrm{a} O u t}$ of limits data point. Shaded line: removed data point. 
Table 14. Detailed Results for the $\mathrm{CO}_{2}+[\mathrm{bmim}]\left[\mathrm{BF}_{4}\right]$ at $298.15 \mathrm{~K}$ from [5]

\begin{tabular}{|c|c|c|c|c|c|c|c|c|}
\hline \multicolumn{9}{|c|}{$\left(5\right.$ data points) $\mathrm{k}_{\mathrm{ij}}=0.4961, \mathrm{~A}_{12}=1249.692, \mathrm{~A}_{21}=298.008,|\Delta \mathrm{P}|(\%)=3.1$} \\
\hline 5300.9 & 5219.2 & -1.5 & 0.010 & 0.011 & $11.94^{\mathrm{a}}$ & 0.999235 & 0.000765 & 0.002 \\
\hline 6312.1 & 5890.6 & -6.7 & 0.050 & 0.055 & 9.88 & 0.999845 & 0.000155 & 0.010 \\
\hline 32905.3 & 33149.1 & 0.7 & 0.400 & 0.400 & 0.21 & 0.999978 & 0.000022 & 0.069 \\
\hline 31530.0 & 31044.4 & -1.5 & 0.700 & 0.705 & 0.62 & 0.999987 & 0.000013 & 0.116 \\
\hline 30081.1 & 30111.1 & 0.1 & 1.000 & 0.998 & -0.13 & 0.999990 & 0.000010 & 0.158 \\
\hline 45205.2 & & & 2.000 & 2.002 & 0.11 & 0.999994 & 0.000006 & 0.277 \\
\hline
\end{tabular}

${ }^{\mathrm{a} O u t}$ of limits data point.

Table 15. Detailed Results for the $\mathrm{CHF}_{3}+[\mathrm{bmim}]\left[\mathrm{PF}_{6}\right]$ at 323.10 K from [8]

\begin{tabular}{|c|c|c|c|c|c|c|c|c|}
\hline \multicolumn{9}{|c|}{$(8$ data points $) \mathrm{k}_{\mathrm{ij}}=0.9522, \mathrm{~A}_{12}=-1985.123, \mathrm{~A}_{21}=3675.940,|\Delta \mathrm{P}|(\%)=4.0$} \\
\hline 7401.2 & 8459.8 & 14.3 & 0.050 & 0.041 & $-18.57^{\mathrm{a}}$ & 0.9998576 & 0.0001424 & 0.005 \\
\hline 51290.7 & 56615.4 & 10.4 & 0.100 & 0.089 & -10.44 & 0.9999357 & 0.0000643 & 0.011 \\
\hline 58146.3 & 56810.9 & -2.3 & 0.700 & 0.703 & 0.36 & 0.9999925 & 0.0000075 & 0.086 \\
\hline 60305.3 & 61356.3 & 1.7 & 1.000 & 0.995 & -0.56 & 0.9999949 & 0.0000051 & 0.121 \\
\hline 42105.9 & 42865.8 & 1.8 & 1.299 & 1.299 & -0.01 & 0.9999963 & 0.0000037 & 0.156 \\
\hline \multicolumn{9}{|c|}{$(7$ data points $) \mathrm{k}_{\mathrm{ij}}=0.8961, \mathrm{~A}_{12}=-1917.752, \mathrm{~A}_{21}=3550.764,|\Delta \mathrm{P}|(\%)=1.9$} \\
\hline 50441.7 & 55778.4 & 10.6 & 0.0996 & 0.0888 & -10.83 & 0.9999352 & 0.0000648 & 0.011 \\
\hline 54802.0 & 53575.3 & -2.2 & 0.3996 & 0.4051 & 1.38 & 0.9999862 & 0.0000138 & 0.050 \\
\hline 55614.6 & 54489.0 & -2.0 & 0.7004 & 0.7021 & 0.24 & 0.9999922 & 0.0000078 & 0.086 \\
\hline 56820.1 & 57916.9 & 1.9 & 1.0004 & 0.9945 & -0.59 & 0.9999947 & 0.0000053 & 0.121 \\
\hline 39149.7 & 39896.6 & 1.9 & 1.2993 & 1.2995 & 0.02 & 0.9999960 & 0.0000040 & 0.156 \\
\hline 99935.3 & 98824.2 & -1.1 & 1.5001 & 1.5029 & 0.19 & 0.9999966 & 0.0000034 & 0.179 \\
\hline
\end{tabular}

${ }^{a}$ Out of limits data point. Shaded line: removed data point. 
Table 16. Detailed Results for the $\mathrm{CHF}_{3}+[\mathrm{bmim}]\left[\mathrm{PF}_{6}\right]$ at 323.10 K from [6]

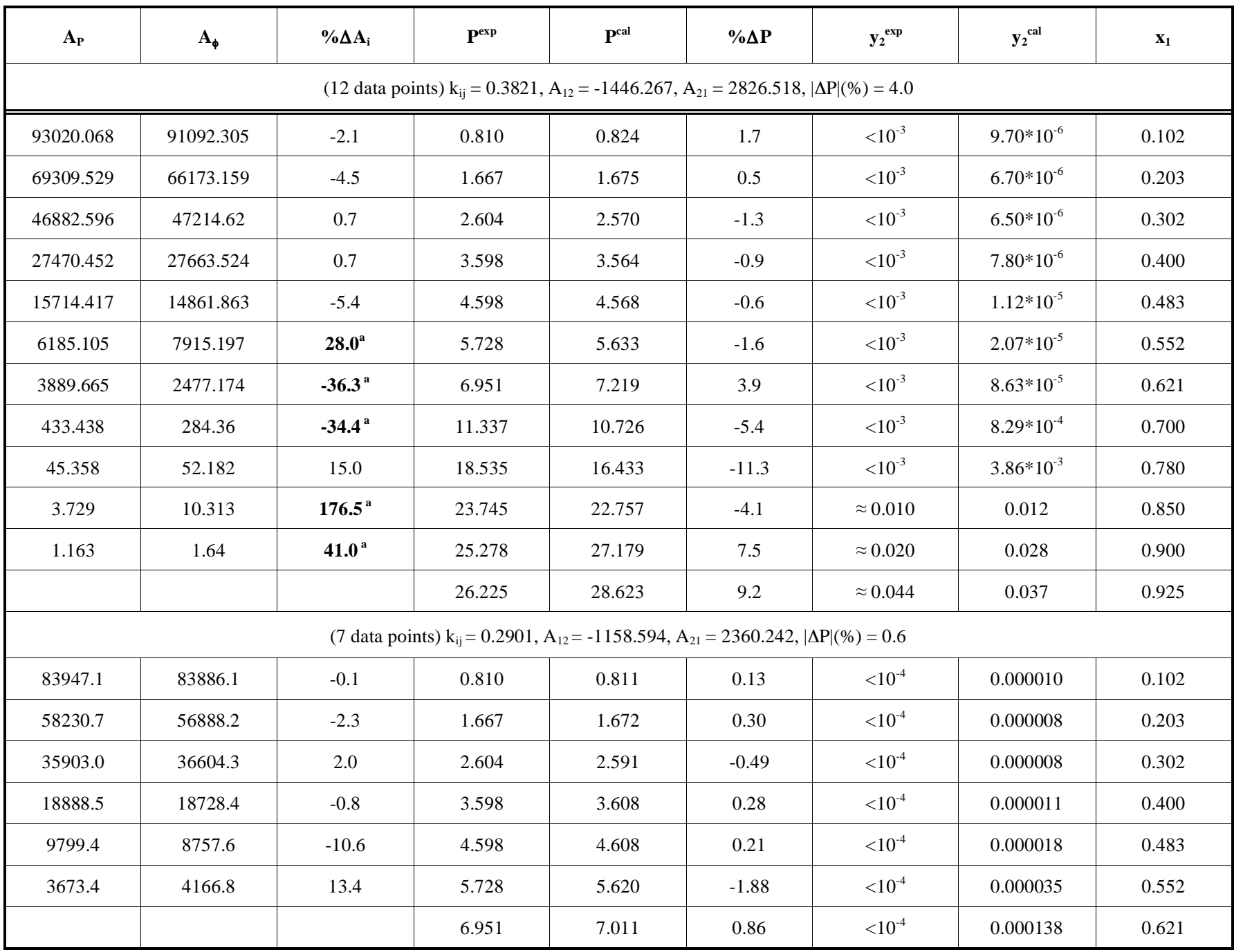

${ }^{\mathrm{a} O u t}$ of limits data point. Shaded line: removed data point.

\section{ACKNOWLEDGEMENTS}

The financial support of CAPES and FAPESP (Brazil) is gratefully acknowledged.

\section{NOMENCLATURE}

\section{Symbols}

$A, B, C, D=$ Parameters in interpolation functions

$A \quad=\quad$ Area

$A^{E} \quad=\quad$ Excess Helmholtz energy

$A_{i j} \quad=$ Energy interaction parameter in UNIQUAC

$a, a_{c}, b=$ Constants in Peng-Robinson EoS

$a_{m}, b_{m}=$ Mixture constants in Peng-Robinson EoS

$E A \quad=\quad$ Error in calculated areas

$F=$ Dependence on the acentric factor in the $\alpha$ function

$G^{E} \quad=\quad$ Excess Gibbs energy
$=$ Binary interaction parameter

$=$ Pressure

$=$ Structural parameter for surface area in UNIQUAC

$=$ Universal gas constant

$=$ Structural parameter for volume in UNIQUAC

$=$ Temperature

$=$ Critical temperature

$=$ Reduced temperature $\left(T_{r}=T / T_{c}\right)$

$=$ Molar volume

$=$ Mole fraction of supercritical fluid in the vapor phase

$=$ Mole fraction in the liquid phase

$=$ Compressibility factor

$=$ Coordination number in UNIQUAC $(z=10)$ 


$\begin{array}{lll}\text { Abbreviations } & \\ \text { EOS } & =\text { Equation of State } \\ N F C & = & \text { Not fully consistent } \\ T C & = & \text { Thermodynamically consistent } \\ T I & = & \text { Thermodynamically inconsistent } \\ \text { UNIQUAC } & = & \text { UNIversal-QUAsiChemical model } \\ \% \triangle & = & \text { Percent deviation }\end{array}$

\section{Greek letters}

$\begin{array}{lll}\alpha(T) & =\begin{array}{l}\text { Temperature function in the Peng- } \\ \text { Robinson EoS }\end{array} \\ \omega & =\text { Acentric factor } \\ \Omega & =\begin{array}{l}\text { Characteristic constant in Wong-Sandler } \\ \text { mixing rule }\end{array} \\ \Phi & =\text { Volume fraction in UNIQUAC } \\ \theta & =\text { Surface area fraction in UNIQUAC } \\ \Delta & =\text { Interval (for temperature, pressure and } \\ \phi \quad & =\text { Fugacity coefficient } \\ \tau & =\text { Exponential interaction parameter in } \\ \sigma & =\text { UNIQUAC } \\ & \text { Standard deviation in measured properties }\end{array}$

\section{Super/subscripts}

$\begin{array}{ll}\text { A } & =\text { Area } \\ \text { cal } & =\text { Calculated } \\ E & =\text { Excess property } \\ \text { comb } & =\text { Combinatorial } \\ \text { exp } & =\text { Experimental } \\ \text { fluid } & =\text { Supercritical fluid } \\ i, j & =\text { Components } \\ P & =\text { Pressure } \\ \text { res } & =\text { Residual } \\ Y & =\text { Vapor-phase composition } \\ \infty & =\text { Infinite pressure }\end{array}$

\section{APPENDIX A: $P X$ DIAGRAM FROM ISOPLETHS}

By interpolating between isopleths, it is possible to plot the $P x$ diagram at constant temperature. Since both bubbleand dew-points are available in several isopleths, each $P x$ diagram illustrates both the solubility of the supercritical fluid in the ionic liquid-rich phase and the solubility of the ionic liquid in the supercritical fluid phase. Then, values of other than the known discrete points may be needed (i.e., interpolation). This process, for discrete data, is performed by fitting an approximating function to the discrete data set. Many types of approximating functions can be used and several authors calculated $P x$ diagram from isopleths, but without recommending one specific method for the best interpolation or curve fitted for the isopleths. A $P x$ diagram appears in Fig. (A.1).

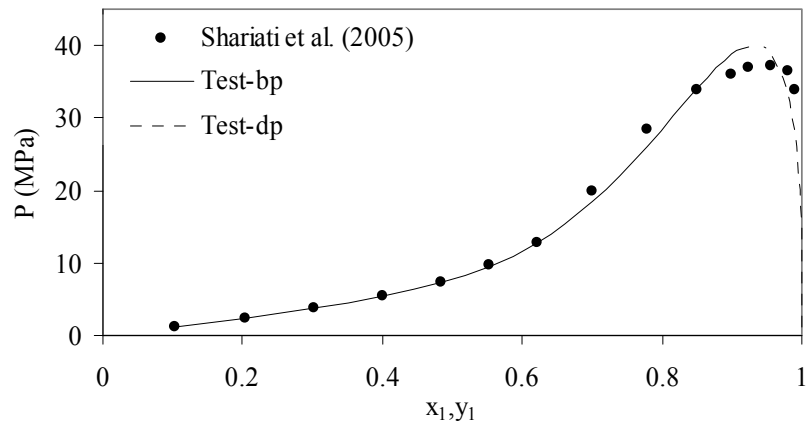

Fig. (A.1). $P x$ diagram for the system supercritical $\mathrm{CHF}_{3}+$ $\left[\mathrm{bmim}\left[\mathrm{PF}_{6}\right]\right.$ at $348.10 \mathrm{~K}$.

In this work, there were used interpolation functions for a set of discrete data in two ways: exact fit, such as cubic spline [29] and approximate fit, by using low degree polynomials $[17,18]$, where the parameters were fitted through the least squares approximation. Five interpolation functions were tested.

The method for select the best interpolation function is based on the hypothesis that experimental error should be randomly distributed. The error defined in order to accept the interpolation function as accurate for the data is based on the work by Hoffman [30], using the general equation of error interpolation of Weierstrass approximation theorem. Then, the error defined $(\%|\Delta E|)$ used temperature $T$ as the independent measured variable and pressure $P$ as the dependent measured variable for the isopleths data. In order to confirm this error, several calculations of errors in the interpolated experimental data were performed. The absolute average percent deviations for the interpolation $\%|\Delta E|$ is defined as:

$\%|\Delta \mathrm{E}|=\frac{100}{\mathrm{~N}} \sum_{\mathrm{i}=1}^{\mathrm{N}}\left|\mathrm{P}_{\mathrm{i}}^{\exp }-\mathrm{f}\left(\mathrm{T}_{1}^{\exp }, . . \mathrm{T}_{\mathrm{j}}^{\exp }, . . \mathrm{T}_{\mathrm{N}}^{\exp }\right)_{\mathrm{j} \neq \mathrm{i}}\right| / \mathrm{P}_{\mathrm{i}}^{\exp }$

where $N$ is the number of data points, $T_{i}^{e x p}$ is the experimental temperature at point " $i$ ", $P_{i}^{\text {exp }}$ is the experimental pressure at point " $i$ ", and $f$ is the interpolated function fitted with all other experimental data points but " $i$ " and evaluated at " $i$ ". The interpolation error is used on five interpolation functions over each isopleth; so, the interpolation function with the minimum value of $\%|\Delta E|$ is established as the optimal for the isopleth. After that, the chosen interpolation function is fitted with all experimental data and used to plot the $P x$ diagram. In this way, the optimal interpolation function has the natural tendency of data, suffers a minimal influence by the removing of one data point, does not present over fitting and has the best representation for large or rough data sets.

The isopleths from Shariati and co-workers used in the consistency thermodynamic were used; one set of such data is shown in Fig. (A.1). The interpolation functions and the results are shown in Table A1. In this table, $N_{i}$ is the number of isopleths interpolated, $\%|\Delta E|$ is the average percent deviations for the interpolation, $\%|\Delta P|$ is the absolute average percent deviation for pressure, and $A, B, C$ and $D$ are the fitted parameters for the interpolation functions. 
Table A1. Interpolation Functions, Errors $(\%|\Delta E|)$ and Relative Deviation in Pressure $(\%|\Delta P|)$

\begin{tabular}{|c|c|c|c|}
\hline Function & $\mathbf{N}_{\mathbf{i}}$ & $\boldsymbol{\%}|\mathbf{E}|$ & $\%|\Delta \mathbf{P}|$ \\
\hline \hline cubic spline & 8 & 0.20 & 0.00 \\
\hline $\mathrm{P}=\mathrm{AT}^{2}+\mathrm{BT}+\mathrm{C}$ & 9 & 0.28 & 0.22 \\
\hline $\mathrm{P}=\mathrm{AT}^{3}+\mathrm{BT}^{2}+\mathrm{CT}+\mathrm{D}$ & 11 & 0.19 & 0.11 \\
\hline $\mathrm{P}=\mathrm{e}^{(\mathrm{A}+\mathrm{B} / \mathrm{T})}$ & 1 & 0.53 & 0.45 \\
\hline $\mathrm{P}=\mathrm{e}^{\left(\mathrm{A}+\mathrm{B} / \mathrm{T}^{2}\right)}$ & 1 & 0.57 & 0.50 \\
\hline
\end{tabular}

Table A1 shows that the value of $\%|\Delta E|$ is always greater than $\%|\Delta P|$. Also, it shows that the cubic spline has $\%|\Delta P|=$ 0 , because cubic spline yields the exact experimental pressure $P_{i}$ for each experimental temperature $T_{i}$. In contrast, $\%|\Delta E|$ by definition uses a function fitted without the data point " $i$ ", evaluated in the point " $i$ " and then does not allow over fitting.

For systems with $P x$ diagram from interpolated isopleths data, the mean value of $\%|\Delta E|$ for all isopleths was used for $\sigma_{P}$. The mean value of $\%|\Delta E|$ for $\mathrm{CO}_{2}+[\mathrm{bmim}]\left[\mathrm{PF}_{6}\right], \mathrm{CO}_{2}+$ $[\mathrm{bmim}]\left[\mathrm{BF}_{4}\right]$ and $\mathrm{CHF}_{3}+[\mathrm{bmim}]\left[\mathrm{PF}_{6}\right]$ are $0.39 \%, 0.33 \%$ and $0.13 \%$, respectively. These values are within the reported experimental error, which has a range from $0.04 \%$ for high pressure to $1.7 \%$ for low pressure. Considering these values, when a reported experimental data set does not show experimental uncertainties, the value $\sigma_{P}=0.1 \%$ was used.

\section{REFERENCES}

[1] L.A. Blanchard, Z. Gu and J.F. Brennecke, "High-pressure phase behavior of ionic liquid/ $/ \mathrm{CO}_{2}$ systems," J. Phys. Chem. B, vol. 105, pp. 2437-2444, March 2001.

[2] A. Pérez-Salado Kamps, D. Tuma, J. Xia and G. Maurer, "Solubility of $\mathrm{CO}_{2}$ in the ionic liquid [bmim] $\left[\mathrm{PF}_{6}\right]$, J. Chem. Eng. Data, vol. 48, pp. 746-849, June 2003 .

[3] Z. Liu, W. Wu, B. Han, Z. Dong, G. Zhao, J. Wang, T. Jiang and G. Yang, "Study on the phase behaviors, viscosities, and thermodynamic properties of $\mathrm{CO}_{2} /\left[\mathrm{C}_{4} \mathrm{mim}\right]\left[\mathrm{PF}_{6}\right] /$ methanol system at elevated pressures," Chem. Eur. J., vol 9, pp. 3897-3903, August 2003.

[4] S.V.N.K. Aki, B.R. Mellein, E.M. Saurer and J.F. Brennecke, "High-pressure phase behavior of carbon dioxide with imidazolium-based ionic liquids," J. Phys. Chem. B, vol. 108, pp. 2035520365, December 2004

[5] M.B. Shiflett and A. Yokozeki, "Solubilities and diffusivities of carbon dioxide in ionic liquids: $[\mathrm{bmim}]\left[\mathrm{PF}_{6}\right]$ and $[\mathrm{bmim}]\left[\mathrm{BF}_{4}\right]$," Ind. Eng. Chem. Res., vol. 44, pp. 4453-4464, June 2005.

[6] A. Shariati. K. Gutkowski and C.J. Peters, "Comparison of the phase behavior of some selected binary systems with ionic liquids," AIChE J., vol. 51, pp. 1532-1540, May 2005.

[7] M.C. Kroon, A. Shariati, M. Costantini, J. Van Spronsen, G. Witkamp, R.A. Sheldon and C.J. Peters, "High-pressure phase behavior of systems with ionic liquids: Part V. the binary system carbon dioxide + 1-butyl-3-methylimidazolium tetrafluoroborate," $J$. Chem. Eng. Data, vol. 50, pp. 173-176, February 2005.
M.B. Shiflett and A. Yokozeki, "Solubility and diffusivity of hydrofluorocarbons in room-temperature ionic liquids," AIChE J. vol. 52, pp. 1205-1219, March 2006.

[9] J.D. Raal and A.D. Mühlbauer, Phase Equilibria: Measurement and Computation, Taylor \& Francis, Washington, DC, 1998.

[10] J.M. Prausnitz, R.N. Lichtenthaler and E.G. Azevedo, Molecular Thermodynamics of Fluid Phase Equilibria, $3^{\text {rd }}$ edition, Prentice Hall, Englewood Cliffs, New Jersey, 1999.

[11] O.L. Jackson and R.A. Wilsak, "Thermodynamic consistency tests based on the Gibbs-Duhem equation applied to isothermal, binary vapor-liquid equilibrium data: data evaluation and model testing," Fluid Phase Equilib., vol. 103, pp. 155-197, February 1995.

[12] A. Bertucco, M. Barolo and N. Elvassore, "Thermodynamic consistency of vapor-liquid equilibrium data at high-pressure," AIChE J., vol. 43, pp. 547-554, February 1997.

[13] J.O. Valderrama and V.H. Âlvarez, "A versatile thermodynamic consistency test for incomplete phase equilibrium data of highpressure gas-liquid mixtures," Fluid Phase Equilib., vol. 226, pp. 149-159, December 2004

[14] P. Wasserscheid and T. Welton, Ionic Liquids in Synthesis, WileyVCH, Weinheim, 2002.

[15] J.O. Valderrama and P.A. Robles, "Critical properties, normal boiling temperatures, and acentric factors of fifty ionic liquids," Ind. Eng. Chem. Res., vol. 46, pp. 1338-1344, February 2007.

[16] V.H. Álvarez and M. Aznar, "Vapor-liquid equilibrium of binary systems ionic liquid + supercritical $\left\{\mathrm{CO}_{2}\right.$ or $\left.\mathrm{CHF}_{3}\right\}$ and ionic liquid + hydrocarbons using Peng-Robinson equation of state," XXII Interamerican Congress of Chemical Engineering, 672, Buenos Aires, October 2006.

[17] A.R. Cruz Duarte, M.M. Mooijer-van den Heuvel, C.M.M. Duarte and C.J. Peters, "Measurement and modelling of bubble and dew points in the binary systems carbon dioxide + cyclobutanone and propane + cyclobutanone," Fluid Phase Equilib., vol. 214, pp. 121136, December 2003.

[18] C.J. Peters, J.L. De Roo and R.N. Lichtenthaler, "Measurements and calculations of phase equilibria of binary mixtures of ethane + eicosane. Part 1: vapour + liquid equilibria," Fluid Phase Equilib., vol. 34, pp. 287-308, July 1987.

[19] V.H. Alvarez, R. Larico, Y. Yanos and M. Aznar "Parameter estimation for VLE calculation by global minimization: genetic algorithm," Braz. J. Chem. Eng., 2007, in press.

[20] D.Y. Peng and D.B. Robinson, "A new two-constant equation of state," Ind. Eng. Chem. Fund., vol. 15, pp. 59-64, February 1976.

[21] H.C. Van Ness, S.M. Byer and R.E. Gibbs, "Vapor-liquid equilibrium. Part 1. An appraisal of data reduction methods," AIChE J., vol. 19, pp. 238-244, March 1973.

[22] D.H.S. Wong and S.I. Sandler, "A theoretically correct mixing rule for cubic equations of state," AIChE J., vol. 38, pp. 671-680, May 1992.

[23] D.S. Abrams and J.M. Prausnitz, "Statistical thermodynamics of liquid-mixtures - a new expression for the excess Gibbs energy of partly or completely miscible systems," AIChE J., vol. 21, pp. 116128, January 1975 .

[24] J. Mollerup, "A note on the derivation of mixing rules from excess Gibbs energy models," Fluid Phase Equilib., vol. 25, pp. 323-327, March 1986.

[25] T. Banerjee, M.K. Singh and A. Khanna "Prediction of binary VLE for imidazolium based ionic liquid systems using COSMORS," Ind. Eng. Chem. Res., vol. 45, pp. 3207-3219, April 2006.

[26] R.H. Perry, D.W. Green and J.O. Maloney, Perry's Chemical Engineers' Handbook, $7^{\text {th }}$ ed., McGraw-Hill, New York, 1999.

[27] V.H. Alvarez, R.M. Maduro and M. Aznar, "Robust and Efficient Implementation of Strategies for Chemical Engineering Regression Problems", $18^{\text {th }}$ European Symposium on Computer Aided Process Engineering, 2008, accepted.

[28] J.O. Valderrama and V.H. Álvarez, "Correct way of reporting results when modelling supercritical phase equilibria using equations of state," Can. J. Chem. Eng., vol. 83, pp. 578-581, June 2005

[29] W.H. Press, S.A. Teukolsky, W.T. Vetterling amd B.P. Flannery, Numerical Recipes in Fortran 77. The Art of Scientific Computing, Vol. $1,2^{\text {nd }}$ ed., Cambridge University Press, New York, 1992.

[30] J.D. Hoffman, Numerical Methods for Engineers and Scientists, $2^{\text {nd }}$ ed., Marcel Dekker, Inc., New York, 2001.

[31] Diadem Public 1.2. The DIPPR Information and Data Evaluation Manager, 2000. 